\title{
CHARACTERIZATION OF HYDRODYNAMIC PROCESSES DRIVING TIDAL RIVER ISLAND SHORELINE CHANGE
}

\author{
Alexandra Muscalus, Georgia Institute of Technology, amuscalus@gatech.edu \\ Kevin Haas, Georgia Institute of Technology, khaas@gatech.edu
}

\begin{abstract}
INTRODUCTION
Bird/Long Island is a dredge-spoil island located between the north and south channels near the inlet of the Savannah River at the border of Georgia and South Carolina (Figure 1). The island is in a tidally dominant environment and contains cultural and natural resources, including remnants of a Civil War era artillery battery. As a wetland mitigation bank, it is particularly important to the state of Georgia. However, these resources are under threat from documented and ongoing sea level rise, shoreline change (i.e., erosion and accretion) from natural and anthropogenic causes, and land subsidence. In addition to substantial tidal and freshwater flows, the island is subject to locally-generated wind waves primarily from northeast winds, as well as wake from the large container ships transiting to and from the Port of Savannah. A previous study examined the effects of wind and vessel-generated waves on shoreline retreat for the Fort Pulaski National Monument on nearby Cockspur Island(Houser 2010). The study concluded that while the vessel-generated waves account for nearly $25 \%$ of the energy, the wind waves during storm events with increased water levels accounted for the majority of the marsh retreat. Although the proximity of this previous study site to Bird/Long Island is relevant, the different orientations of the islands and the narrowing of the channel create a different hydrodynamic environment. The present work uses field data to characterize the hydrodynamic processes affecting Bird/Long Island, which will improve modeling of its shoreline change.
\end{abstract}

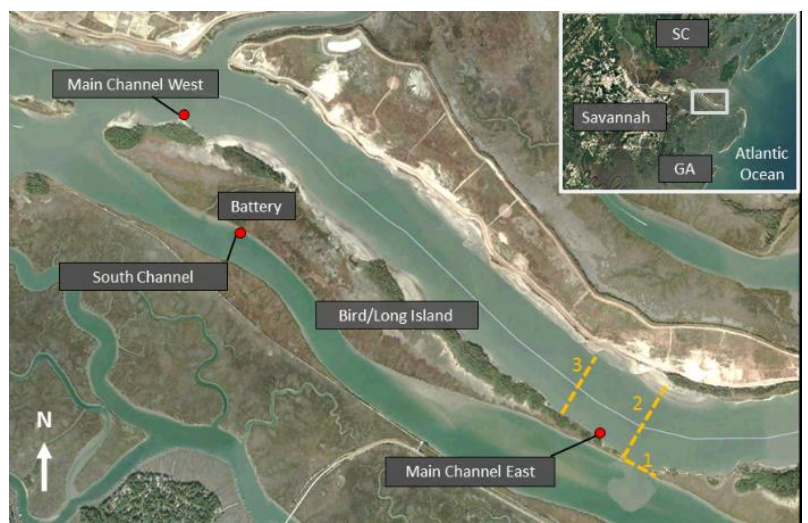

Figure 1 - Map of Bird/Long Island. Red dots indicate deployment sites and dashed lines represent transect measurements.

\section{MEASUREMENTS}

During two long-term deployments (spring 2017 and fall 2017), three Aquadopp current profilers were deployed in shallow water near the island to record current velocities and water level, including burst sampling of waves and ship wake measured every thirty (spring) and twenty (fall) minutes. Two Aquadopps were placed in the north channel, and a third in the south channel, as shown in Figure 1. In addition, during three separate multi-day deployments, three pressure transducers were also installed near the Aquadopp locations to provide continuous measurements of wind waves and ship wake. During the pressure transducer deployment, a camera was installed on the island to capture images of the north channel every thirty seconds to provide visual evidence of water traffic. At the end of the spring deployment, an acoustic Doppler current profiler mounted on a boat was used to measure transects of across-channel and alongchannel current velocity. Data were collected along three transects: two spanning the north channel and one spanning a washout between the channels as shown in Figure 1.

\section{RESULTS}

Figure 2 provides the month-long time series of raw and de-tided water level, water temperature, wind speed, and wind direction. A period of increased wind speed directed from the northeast ( 30 degrees) beginning October 17th had a sufficiently large onshore component to increase the water level in the channel. In contrast, beginning October 29th a period of increased wind speed directed from the northwest ( 300 degrees) induced the opposite effect; the offshore component of the wind pushed water out of the channel and decreased the water level.
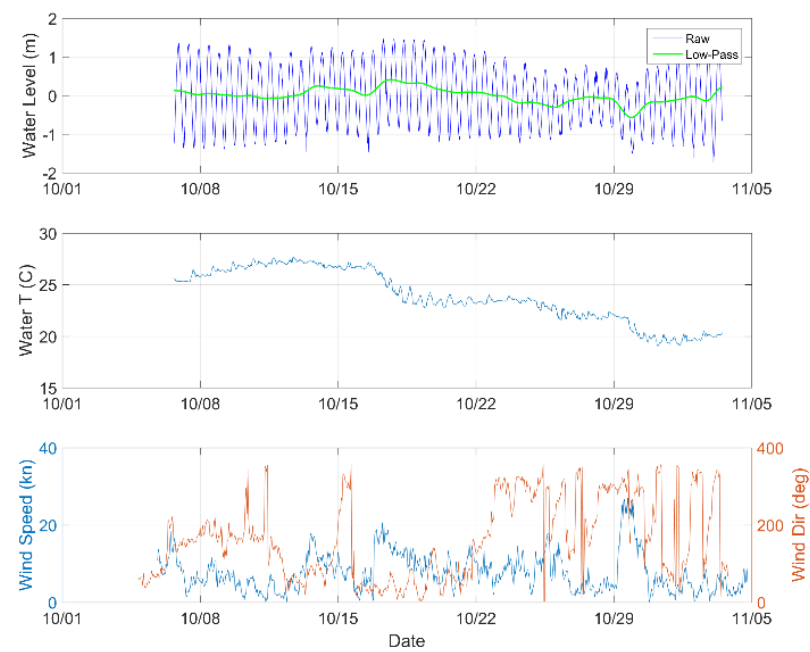

Figure 2 - Raw and de-tided water level (upper) and temperature (middle) data collected in the Main Channel during the Fall deployment demonstrate changes consistent with strong wind events (lower) indicated by data obtained from the Fort Pulaski NOAA meteorological station.

Due to the sheltered characteristic of the island, set well inside the Savannah River entrance, the wind waves were 
all locally generated with a relatively small fetch, and had maximum wave heights of $5-15 \mathrm{~cm}$. On the other hand, the ship wake was significant with maximum drawdown to surge elevations of nearly $2 \mathrm{~m}$.

Figure 3 shows low-pass filtered times series of the depth-averaged velocity and water level resulting from the passage of an inbound container ship (top). During the water level drawdown, water velocity increases in the southeastward direction, towards the ship. During the surge, the water rapidly and fully reverses direction and flows towards the northwest, in the direction of the ship's travel. This is congruent with flow in the direction of the incoming wake.

Similarly, the bottom panel in Figure 3 shows the velocity time series during an outbound ship wake event. Outbound ships are traveling from the northwest to the southeast (e.g. see Figure 1), such that during the water level drawdown, water velocity increases in the northwest direction, towards the ship. During the surge, the magnitude of the velocity weakens and oscillates slightly until it returns to its previous state. In most outbound cases, a full reversal of the flow in the direction of the ship's travel - as is seen in most inbound ship wake events - is not observed. Seiching in both channels was also observed for up to an hour after both inbound and outbound ship passage events.
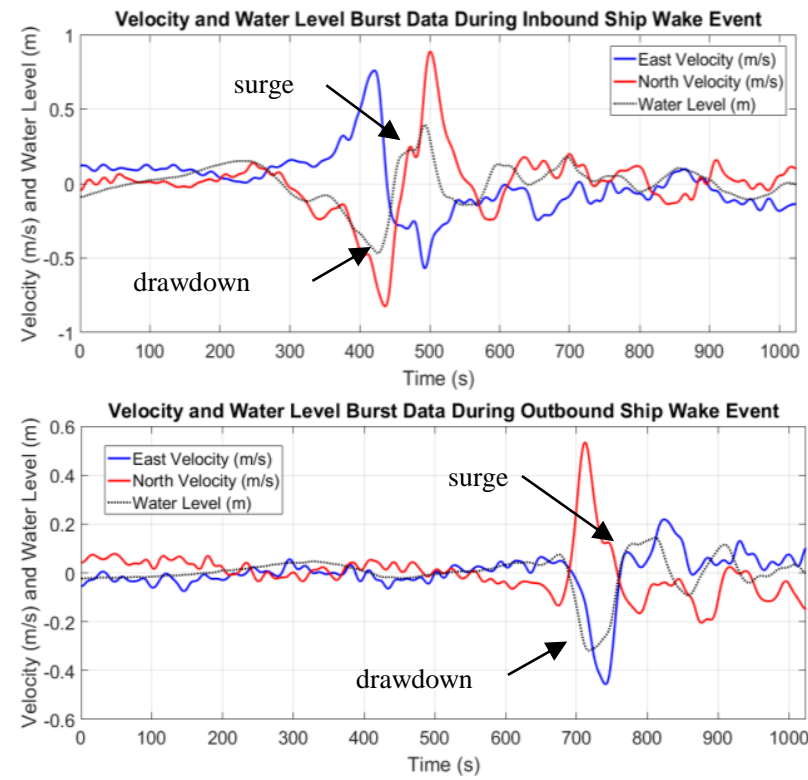

Figure 3 - Low-pass filtered time series of water level and current velocity demonstrating the characteristic effects of an inbound (top) and outbound (bottom) container ship wake.

These wake events happen on a regular basis with the high activity level on the Savannah River from the port and other boat traffic. Figure 4 provides the time series of pressure transducer water level data at the three deployment sites obtained during 48-hour deployments in October. Over 50 watercraft were observed passing by the Main Channel West site by the camera; over these, 22 were visually identified as container ships. Water level fluctuations are significantly increased in the Main Channel (red and blue time series) when ships pass by the site; fluctuations in the South Channel (orange time series) are present as well, though smaller in magnitude. Slight offsets in the time period of fluctuations are due to the direction of ship travel; for example, the wake of an inbound ship will be observed at the Main Channel East site before the Main Channel West and South Channel sites. For this reason, the direction of ship travel is indicated by the color of the vertical dashed line on the figure.

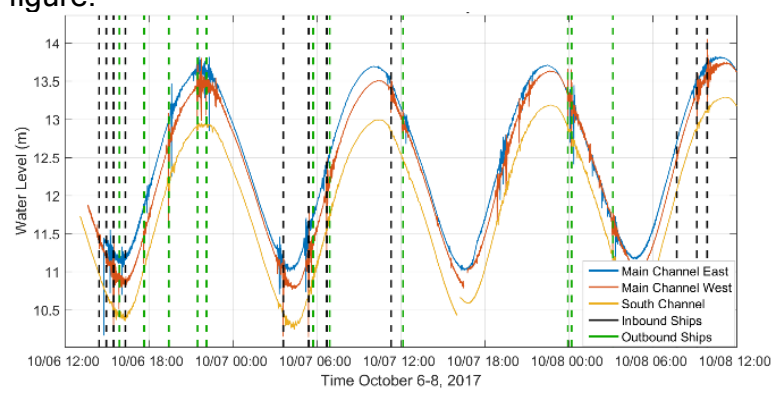

Figure 4 - Water level time series for three sites during October 6-8th. Vertical dashed lines indicate times during which container ships were observed by a camera passing the Main Channel West site.

As demonstrated in Figure 5 (upper), the across-channel current velocity profiles shows cross-channel circulation in the north channel; $0.2 \mathrm{~m} / \mathrm{s}$ flows in opposite directions were observed to occur simultaneously at different depths. The along-channel current velocity profiles demonstrate various complex flow conditions with significant vertical and lateral structure. Current magnitudes reached $1.5 \mathrm{~m} / \mathrm{s}$, with the largest currents generally at the water surface. Tidal flow reversal was also observed to be non-uniform throughout the channel in both the vertical and lateral directions.

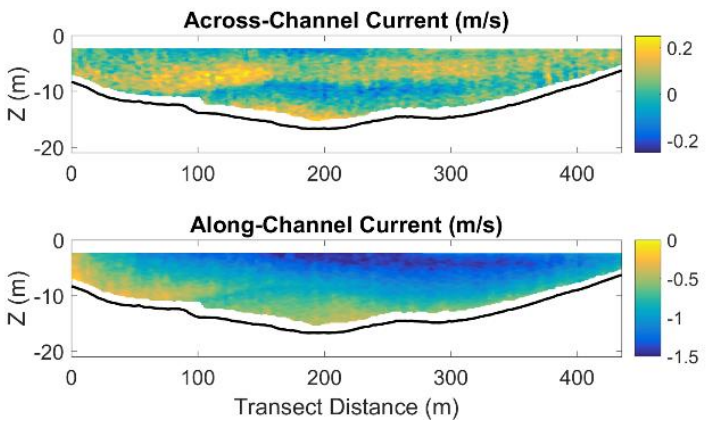

Figure 5 - Across-channel (upper) and along-channel (lower) current velocities of a transect across the north channel near Bird/Long Island.

\section{REFERENCES}

Houser (2010): Relative importance of vessel-generated and wind waves to salt marsh erosion in a restricted fetch environment, Journal of Coastal Research, vol. 26, pp. 230-240. 